SILVA, Marcos Vinicius Viana da; SILVA, José Everton da. O estatuto da cidade, uma necessidade social e ambiental no sistema democrático. Revista Eletrônica Direito e Política, Programa de PósGraduação Stricto Sensu em Ciência Jurídica da UNIVALI, Itajaí, v.10, n.1, edição especial de 2015. Disponível em: www.univali.br/direitoepolitica - ISSN 1980-7791.

\title{
O ESTATUTO DA CIDADE, UMA NECESSIDADE SOCIAL E AMBIENTAL NO SISTEMA DEMOCRÁTICO
}

\author{
THE STATUTE OF THE CITY, A SOCIAL AND ENVIRONMENTAL NEED AT \\ THE DEMOCRATIC SYSTEM
}

\author{
Marcos Vinicius Viana da Silva ${ }^{1}$ \\ José Everton da Silva²
}

SUMÁRIO: Introdução; 1 . Aspectos históricos da questão urbana; 2. Sociedade democrática ; 3. Plano diretor; 4. Participação popular como princípio e como condição de legitimação; 4.1 A participação popular na criação de plano diretor: uma garantia constitucional; Considerações finais; Referências das fontes citadas

RESUMO: As cidades brasileiras se desenvolveram de maneira desorganizada ao longo dos anos, quer seja por fatores locais, ou ainda por processos de evolução internacional. Independente dos motivos, verifica-se que o desenvolvimento e o processo de expansão da cidade deterioram o ambiente urbano, provoca desorganização social, gera carência de habitação, emprego, problemas de higiene e saneamento básico. Diante de tanta problemática surge a necessidade de efetivação de um Plano Diretor para as cidades, que venha respeitar a então diretriz norteadora da política urbana no Brasil, instituída pela Lei 10.257/2001 Estatuto da Cidade. Dito isto, a presente pesquisa objetiva analisar a importância da gestão democrática como instrumento essencial para implementação do Plano Diretor. Para tanto fora aplicado o método indutivo, além das técnicas de referente e categoria, além da revisão de literatura.

Palavras-Chave: Direito Social; Estatuto das Cidades; Plano Diretor; Participação Popular.

\footnotetext{
1 Acadêmico do Programa de Pós-Graduação Stricto Sensu em Ciência Jurídica da UNIVALI (mestrado), residente da cidade de Itajaí/SC, Brasil. Endereço eletrônico: maome@univali.br.

2 Acadêmico do Programa de Pós-Graduação Stricto Sensu em Ciência Jurídica da UNIVALI (doutorado), residente da cidade de Itajaí/SC, Brasil. Endereço eletrônico: caminha@univali.br.
} 
SILVA, Marcos Vinicius Viana da; SILVA, José Everton da. O estatuto da cidade, uma necessidade social e ambiental no sistema democrático. Revista Eletrônica Direito e Política, Programa de PósGraduação Stricto Sensu em Ciência Jurídica da UNIVALI, Itajaí, v.10, n.1, edição especial de 2015. Disponível em: www.univali.br/direitoepolitica - ISSN 1980-7791.

ABSTRACT: Brazilian cities developed in a disorganized way over the years, either by local factors, or by processes of international developments. Independent of the reasons, it appears that the process of development and expansion of the city's deteriorate urban environment , causing social disruption, creates shortage of housing, employment, problems of hygiene and sanitation. Faced with such problems appears a need to execution of a Director Plan for the cities, which will then respect the guiding directive of urban policy in Brazil, introduced by Law 10,257 / 2001 - Statute of the City. Said this, this research aims to analyze the importance of democratic governance as an essential instrument for implementation of the Director Plan. Was applied the inductive method, in addition to techniques and related category, besides the literature review.

Keywords: Statute of the City, Social Law, Director Plan, Citizen Participation.

\section{INTRODUÇÃO}

A ideia de sustentabilidade liga-se diretamente ao conceito de estabilidade, de durabilidade. Foi no inicio dos anos 70, em estudos de cunho ecológico (sustentabilidade biológica), que pela primeira vez surge à expressão, que focalizava em primeiro plano a ligação e correlação entre população e os recursos ambientais.

Foi a partir dos anos 80 que sua abrangência foi acentuada, para abarcar as relações entre desenvolvimento e meio ambiente, no processo de preparação da Conferência da ONU, que ocorreu no Rio de Janeiro em 1992.

O termo desenvolvimento sustentável foi cunhado por Maurice Strong ${ }^{3}$ e recebeu da Comissão de declaração do Rio algumas definições: "é aquele que atende às necessidades do presente sem comprometer a possibilidade de as gerações futuras atenderem as suas próprias necessidades"4; no mesmo sentido "é um processo de transformação no qual a exploração dos recursos, a direção dos

\footnotetext{
${ }^{3}$ O conceito de ecodesenvolvimento, lançado por Maurice Strong em junho de 1973, consistia na definição de um estilo de desenvolvimento adaptado às áreas rurais do Terceiro Mundo, baseado na utilização criteriosa dos recursos locais, sem comprometer o esgotamento da natureza, pois nestes locais ainda havia a possibilidade de tais sociedades não se engajarem na ilusão do crescimento mimético.

4 ONU, Organização das Nações Unidas. Declaração do Rio. Declaração da comissão de Desenvolvimento sustentável da ONU. 1992. p.46.
} 
SILVA, Marcos Vinicius Viana da; SILVA, José Everton da. O estatuto da cidade, uma necessidade social e ambiental no sistema democrático. Revista Eletrônica Direito e Política, Programa de PósGraduação Stricto Sensu em Ciência Jurídica da UNIVALI, Itajaí, v.10, n.1, edição especial de 2015. Disponível em: www.univali.br/direitoepolitica - ISSN 1980-7791.

investimentos, a orientação do desenvolvimento tecnológico" ${ }^{5}$ e a mudança institucional se harmonizam e reforçam o potencial presente e futuro, a fim de atender às necessidades e aspirações humanas.

O conceito de desenvolvimento sustentável é um dos principais conceitos trazidos pelo relatório que a Comissão Mundial sobre Meio Ambiente e Desenvolvimento apresentou à ONU, sob o nome de Nosso Futuro Comum ${ }^{6}$.

Mas desde seu enunciado original, esse conceito tem tido sua abrangência cada vez mais ampliada, servindo de meio de articulação das dimensões econômica, ambiental e social, vistas como indissociáveis.

O elemento central colocado neste texto é o de que somente o cidadão, aquele diretamente envolvido com a cidade e seus destinos, é capaz de tomar as melhores decisões, e encontrar o melhor caminho para sua caminhada.

A questão da governança neste inicio de século XXI, está intimamente associada à questão da sustentabilidade. Não basta mais apenas o desenvolvimento, associada a uma ideia de progresso, o que se busca é uma ideia de desenvolvimento atrelado a um conceito de sustentabilidade.

É nos centros urbanos que se dá a maioria das discussões a respeito da governança e da sustentabilidade, não mais em caráter local, mas até mesmo em caráter transnacional.

A cidade é o um mundo e vice-versa. Portanto, garantir uma ampla e democrática participação popular na elaboração do Plano Diretor, se impõe como medida de inteligência e cidadania.

Para contextualizar o tema, foram levantados os principais aspectos históricos da questão urbana, desde a sua ideia e origem em Roma, passando pelo conceito de

5 ONU, Organização das Nações Unidas. Declaração do Rio. Declaração da comissão de Desenvolvimento sustentável da ONU. 1992. p.49.

${ }^{6}$ ONU, Organização das Nações Unidas. Nosso Futuro Comum/Comissão Mundial Sobre Meio Ambiente e Desenvolvimento. 1992 
SILVA, Marcos Vinicius Viana da; SILVA, José Everton da. O estatuto da cidade, uma necessidade social e ambiental no sistema democrático. Revista Eletrônica Direito e Política, Programa de PósGraduação Stricto Sensu em Ciência Jurídica da UNIVALI, Itajaí, v.10, n.1, edição especial de 2015. Disponível em: www.univali.br/direitoepolitica - ISSN 1980-7791.

cidade no século XVI, pela Revolução Industrial do século XVIII, até chegar ao modelo atual.

Em tópico específico, faz-se breve análise do que vem a ser Estado de direito, absoluto e despótico, e a importância do Estado de direito para garantir a participação democrática dos indivíduos, pela emancipação de uma sociedade politicamente organizada.

Neste sentido, observa-se que não há como definir direito e impor restrições sem garantir a participação da sociedade civil nas políticas públicas, para que exista a democracia em seu sentido pleno.

Dando continuidade, estudar-se-á a natureza jurídica do Plano Diretor no Brasil, seus fundamentos, conceito, modelo, para então analisar os meios de garantir sua implementação, partindo-se após para as considerações finais.

Quanto ao método utilizado, na fase inicial destaca-se o indutivo, através de pesquisa com técnica do Referente, da Categoria e Pesquisa Bibliográfica?.

\section{ASPECTOS HISTÓRICOS DA QUESTÃO URBANA}

A ideia de ambiente urbano está fortemente relacionada, segundo Benevolo ${ }^{8}$, ao "ambiente originário na qual nasce o poderio romano", portanto a partir do surgimento de Roma, foi adotada uma estrutura específica e padronizada de cidades, ideia esta que atravessou os séculos, formatando o modo pelo qual as cidades foram paulatinamente sendo erguidas.

Com o advento da Revolução Industrial a partir da metade do século XVIII, houve efetivamente uma mudança na concepção do conceito de cidade, que

7 PASOLD, Cesar Luiz. Metodologia da Pesquisa Jurídica: Teoria e Prática. 12a Edição revisada. São Paulo: Conceito Editorial, 2011.

${ }^{8}$ BENEVOLO, Leonardo- História da cidade, Perspectiva, 3. ed. 1997. p. 703 
SILVA, Marcos Vinicius Viana da; SILVA, José Everton da. O estatuto da cidade, uma necessidade social e ambiental no sistema democrático. Revista Eletrônica Direito e Política, Programa de PósGraduação Stricto Sensu em Ciência Jurídica da UNIVALI, Itajaí, v.10, n.1, edição especial de 2015. Disponível em: www.univali.br/direitoepolitica - ISSN 1980-7791.

passou a ser "a sede das classes dominantes", diferentemente do campo, que por sua vez era considerado o reduto "das classes subalternas" ${ }^{9}$.

No Brasil, a lógica foi importada da Europa, tendo o mesmo tipo de estruturação urbana, podemos afirmar que as cidades no Brasil, começam a surgir a partir do século XVI, decorrentes da necessidade de estabelecer sistemas de proteção e, por outro lado, pela extensão territorial brasileira. Estes aglomerados considerados até então como vilas, apresentavam-se unicamente com função econômica, e direcionada à "função militar"10.

Baseado nas ideias contidas na constituição de 1988, o conceito de cidade, segundo Fiorillo ${ }^{11}$,

[,,I] passa ter natureza jurídica ambiental, ou seja, a partir de 1988, a cidade deixa de ser observada a partir de regramentos adaptados tão somente aos bens privados ou públicos e passa a ser disciplinada em face da estrutura jurídica do bem ambiental (artigo 225, Constituição da República Federativa do Brasil de 1888) de forma mediata e imediata em decorrência das determinações constitucionais emanadas dos artigos 182 e 183 da Carta Magna. Portanto, a cidade, passa a obedecer à denominada ordem urbanística dentro dos parâmetros jurídicos adaptados ao final do século XX e início do século XXI. ${ }^{12}$

No que se refere às questões urbanísticas, a Constituição da República Federativa do Brasil de 1988, fixou, dentre as competências dos municípios, o dever de promover, no que couber, adequado ordenamento territorial, mediante

\footnotetext{
${ }^{9}$ FIORILLO, Celso Antônio Pacheco. Estatuto da cidade comentado: lei 10.257/2001: lei do meio ambiente artificial. p. 21

10 FIORILLO, Celso Antônio Pacheco. Estatuto da cidade comentado: lei 10.257/2001: lei do meio ambiente artificial. p. 13

11 FIORILLO, Celso Antônio Pacheco. Estatuto da cidade comentado: lei 10.257/2001: lei do meio ambiente artificial. p. 26

12 Conceito jurídico de cidade: [...] os municípios passaram a ter enorme importância no âmbito da República Federativa do Brasil, regendo-se por lei orgânica (art.29 da CRFB, 1988) como passando a ter competência (art. 23, CRFB, 1988) para proteger o meio ambiente, assim combater a poluição em suas formas (art. 23, VI, CRFB,1988). O Poder Público Municipal a partir do que determina o art.182, CRFB, 1988, passa a ser responsável pela execução da política de desenvolvimento urbano (terra urbana, monística associada a ordem econômica e social, para readequar a realidade brasileira)
} 
SILVA, Marcos Vinicius Viana da; SILVA, José Everton da. O estatuto da cidade, uma necessidade social e ambiental no sistema democrático. Revista Eletrônica Direito e Política, Programa de PósGraduação Stricto Sensu em Ciência Jurídica da UNIVALI, Itajaí, v.10, n.1, edição especial de 2015. Disponível em: www.univali.br/direitoepolitica - ISSN 1980-7791.

planejamento e controle do uso, do parcelamento e do solo urbano, conforme dispõe o artigo 30 , inciso VIII ${ }^{13}$.

E, ainda sob esta ótica, Souza ${ }^{14}$ preleciona que

Desenvolvimento urbano se constitui no processo de expansão de cada cidade. Ele também é processo, porém difere da urbanização no sentido de expansão que esta é uma categoria global e desenvolvimento urbano, uma subcategoria daquela. Ele diz respeito a cada cidade, enquanto que a urbanização diz respeito a um processo de todas as cidades.

Todavia, Silva ${ }^{15}$ enfoca uma concepção um pouco mais crítica em relação à urbanização, asseverando que esta "deteriora o ambiente urbano. Provoca a desorganização social, com carência de habitação, desemprego, problemas de higiene e de saneamento básico. Modifica a utilização do solo e transforma a paisagem urbana".

Note-se que a Política de Desenvolvimento Urbano e a Política Ambiental são indissociáveis, pois para elaboração do Plano Diretor se faz necessário respeitar a legislação ambiental, de modo que os bens ambientais possam ser efetivamente preservados. Cavedon ${ }^{16}$, neste aspecto, conceitua:

Para que se obtenha o ordenamento do uso do solo municipal, visando a compatibilização do desenvolvimento da cidade com a preservação dos recursos naturais, torna-se necessária a realização de um detalhado planejamento deste uso do solo, que contemple os aspectos sociais, ambientais, econômicos e culturais da cidade, além das necessidades e aspirações da comunidade. Este planejamento terá como produto final o Plano Diretor, com força executiva e coercitiva de lei, que conterá as diretrizes pelas quais se definirá o conteúdo da Função Social da Propriedade.

13 CAVEDON, Fernanda de Salles; DIEHL, Francelise Pantoja. A influência da política de desenvolvimento urbano no uso da zona costeira de Bombinhas (SC)- XI Semana Nacional da Oceanografia. Anais>Rio Grande: Fundação Universidade de Rio Grande, 1998. pp. 66-67

14 SOUZA, Maria Adélia. Governo urbano. São Paulo: Nobel, 1988. p. 69

15 SILVA, Jose Afonso. Direito urbanístico brasileiro. 2.ed. São Paulo: Malheiros, 1995. p. 421

16 CAVEDON, Fernanda de Salles. Função social e ambiental da propriedade. Florianópolis: Visual books, 2003. p. 70. 
SILVA, Marcos Vinicius Viana da; SILVA, José Everton da. O estatuto da cidade, uma necessidade social e ambiental no sistema democrático. Revista Eletrônica Direito e Política, Programa de PósGraduação Stricto Sensu em Ciência Jurídica da UNIVALI, Itajaí, v.10, n.1, edição especial de 2015. Disponível em: www.univali.br/direitoepolitica - ISSN 1980-7791.

Denota-se do entendimento da autora, que, para efetivar um Plano Diretor é necessário estabelecer um processo; este, no entanto, decorre de uma redefinição do papel do Estado, ao estabelecer a universalização dos direitos de cidadania, por meio da descentralização e gestão democrática de políticas públicas.

A constituição de 1988 faz surgir um novo formato institucional, predominando o caráter difuso e desconcentrado da Administração Pública, conforme estabeleceu o artigo 182 (CRFB/88) que "objetiva ordenar o pleno desenvolvimento das funções sociais da cidade e garantir o bem estar".

Foi, contudo, a Lei no 10.257/2001 ${ }^{17}$ - Estatuto da Cidade, que estabeleceu as diretrizes norteadoras para que a política urbana fosse efetivada por meio de uma gestão democrática, na qual se apresenta com clareza estas inovações:

As inovações contidas no Estatuto da Cidade situam-se em três campos: um conjunto de instrumentos de natureza urbanística voltados a induzir - mais que normatizar - as formas de uso e ocupação do solo, uma concepção de gestão democrática das cidades que incorpora a ideia de participação direta do cidadão (ã) nos processos decisórios sobre seus destinos; e a ampliação de possibilidades de regularização das posses urbanas, até hoje situadas na ambígua fronteira entre o legal e o ilegal.

Para melhor compreender, a necessidade das cidades melhorar sua organização, durante o Congresso de Arquitetura, de 1931, em Atenas, fez com que fossem estabelecidos os quatro pilares básicos e essenciais da ocupação urbana: 1) que fosse assegurado aos homens moradias saudáveis (espaço, ar puro e sol); 2que os espaços para os locais de trabalho fossem organizados, 3- previsão de instalações necessárias ao lazer, e por fim, que fossem estabelecidos contatos ( gestão democrática) entre os diversos atores sociais para a criação de uma rede circulatória, onde ficaria assegurada as necessidades de cada um deles, portanto este documento passa a ser um referencial, quando discute-se que as

17 BRASIL. Vade Mecum. /obra coletiva de autoria da Editora Saraiva com a colaboração de Luiz Roberto Curia, Márcia Cristina Vaz dos Santos Windt e Lívia Céspedes, 12 ed. atual. e ampl. - São Paulo: Saraiva, 2012. 
SILVA, Marcos Vinicius Viana da; SILVA, José Everton da. O estatuto da cidade, uma necessidade social e ambiental no sistema democrático. Revista Eletrônica Direito e Política, Programa de PósGraduação Stricto Sensu em Ciência Jurídica da UNIVALI, Itajaí, v.10, n.1, edição especial de 2015. Disponível em: www.univali.br/direitoepolitica - ISSN 1980-7791.

necessidades básicas de uma cidade passam também pela qualidade de vida de seus moradores.

$\mathrm{Na}$ "Carta de Atenas"18, podemos destacar os seguintes trechos, que reforçam o estabelecido pelo congresso de arquitetura: "[...] é preciso tornar acessível para todos, por meio de uma legislação implacável, uma certa quantidade de bem estar, independente da questão do dinheiro" e com muita ênfase diz: "[...] o sentimento de responsabilidade administrativa e o da solidariedade social são derrotados diariamente pela força viva e sem cessar renovada do interesse privado "[...]", e noutro trecho, adiante, conclui que : "[...] nessa luta, infelizmente desigual, o interesse privado triunfa o mais das vezes, assegurando o sucesso dos mais fortes em detrimento dos mais fracos $[\ldots]^{\prime 19}$.

Assim, a evolução das cidades também é decorrente da conquista de uma década de luta dos movimentos populares, representados por entidades civis, e dos movimentos sociais, em defesa do direito a cidade, por meio de uma gestão democrática, resultando, portanto no mencionado Estatuto da Cidade $^{20}$.

\section{SOCIEDADE DEMOCRÁTICA}

Como pano de fundo da discussão sobre sustentabilidade e governança, é necessário discorrer a respeito da evolução da sociedade democrática, e a respeito do assunto, Bobbio ${ }^{21}$ afirma que:

\footnotetext{
${ }^{18}$ A Carta de Atenas é um documento de compromisso datado de 1933, redigido e assinado por grandes arquitetos e urbanistas internacionais do início do século $X X$, entre os quais se destaca Le Corbusier. A Carta foi redigida como conclusão do Congresso Internacional de Arquitetos e Técnicos de Monumentos Históricos que teve lugar em Atenas, na Grécia, em outubro de 1931. Em 1998, foi elaborada pelo Conselho Europeu de Urbanistas a Nova Carta de Atenas- Segundo a nova carta, a evolução das cidades deve resultar da combinação de distintas forças sociais e das ações dos principais representantes da vida cívica.
}

19 DENHARDT, Robert. Teoria geral de organizações públicas. (trad. Prof. Francisco G. Heidemann. Thompson/ Wadsworth. 2004.

${ }^{20}$ Estatuto da cidade: guia para implementação pelos municípios e cidadãos: Lei n.10.257,10 de julho de 2001, 3a Ed. Brasília: Câmara dos Deputados, Coordenação de Publicações. 2005. p.15.

${ }^{21}$ BOBBIO, Norberto. A era dos direitos. Trad. Carlos Nelson Coutinho. Campus, 1992. p. 61 
SILVA, Marcos Vinicius Viana da; SILVA, José Everton da. O estatuto da cidade, uma necessidade social e ambiental no sistema democrático. Revista Eletrônica Direito e Política, Programa de PósGraduação Stricto Sensu em Ciência Jurídica da UNIVALI, Itajaí, v.10, n.1, edição especial de 2015. Disponível em: www.univali.br/direitoepolitica - ISSN 1980-7791.

[...] é com o nascimento do Estado de direito que ocorre a passagem final do ponto de vista do príncipe para o ponto de vista dos cidadãos. No Estado despótico, os indivíduos singulares só têm deveres e não direitos. No Estado absoluto, os indivíduos possuem, em relação ao soberano, direitos privados. No Estado de direito, o indivíduo tem, em face do Estado, não só direitos privados, mas também direitos públicos. O Estado de direito é o Estado dos cidadãos.

Entende-se, que o Estado de Direito tem uma dimensão excepcional em relação aos modelos anteriores de Estado, pois envolve os direitos privados e públicos, havendo uma emancipação da sociedade em relação ao Estado, assim traduzida nas palavras de Kelsen ${ }^{22}$ :

O Estado é uma sociedade politicamente organizada porque é uma comunidade constituída por uma ordem coercitiva, e essa ordem é o Direito. Entende-se que esta sociedade política está entrelaçada com a autoridade, com o poder e o próprio direito. Possui uma ciência do Estado, mas não de um Estado particular e sim de um Estado em geral, mais amplo, considerado em sua natureza, suas leis, suas formas e seus princípios.

Podemos considerar que em matéria de teoria da democracia, basicamente, temos duas formas de consenso: um baseado nos valores - igualdade e liberdade, por exemplo -, o outro, baseado nas regras do jogo, isto é, nos procedimentos $^{23}$.

Portanto, não há como discorrer sobre democracia sem ressaltar a importância da participação da sociedade civil nas políticas públicas, pois se estas forem propostas apenas sob o prisma do interesse do Estado, não haveria democracia em seu sentido pleno.

\footnotetext{
22 KELSEN, Hans. Teoria geral do direito e do Estado. Tradução de Luís Carlos Borges. São Paulo: Martins Fontes. 1990. p.191.

${ }^{23}$ SARTORI, Giovanni. A teoria da democracia revisitada: o debate contemporâneo. v. 1, [s. I.], Editora Ática, 1994. p. 128.
} 
SILVA, Marcos Vinicius Viana da; SILVA, José Everton da. O estatuto da cidade, uma necessidade social e ambiental no sistema democrático. Revista Eletrônica Direito e Política, Programa de PósGraduação Stricto Sensu em Ciência Jurídica da UNIVALI, Itajaí, v.10, n.1, edição especial de 2015. Disponível em: www.univali.br/direitoepolitica - ISSN 1980-7791.

Por sua vez, Perez ${ }^{24}$ preleciona que, "a participação popular no Estado de Direito proporciona um avanço nas formas de controle da Administração. Destaca-se que através da participação, a coletividade fiscaliza a Administração Pública."

Assim, sob a ótica do objeto desta pesquisa, a essencialidade da democracia está pautada no fortalecimento das parcerias entre a sociedade civil e o Estado, de forma que seu fruto seja uma atuação igualitária, que garanta um equilíbrio tanto no aspecto econômico, quanto para a vida em sociedade. Para Denhardt ${ }^{25}$ "a proposta do Novo Serviço Público está inspirado na teoria política democrática, principalmente quando se refere a conexão entre cidadãos e seus governos e abordagens alternativas à gestão organizacional".

Diante destas considerações é preciso estabelecer conceitos para uma maior clareza na especificação do tema proposto, assim segundo ensina Di Pietro ${ }^{26}$, a administração pública em sentido material é a administração dos interesses da coletividade, cabendo ao gestor público gerir, administrar de forma ética, técnica e transparente a coisa pública, em consonância com as normas legais e administrativas vigentes, de modo a maximizar e aperfeiçoar as demandas que visem atender os anseios da comunidade.

Assim, manifestadamente, não há como atender os anseios da sociedade civil se esta efetivamente não puder participar das decisões, e na medida, que o relacionamento dentro do espaço urbano passou a ser determinado pela autoridade pública, e mesmo que, em dada época fosse necessário, para organizar a vida urbana e manter o patrimônio cultural, atualmente, já não faz mais sentido, se não houver a participação da sociedade civil ${ }^{27}$.

A Constituição da República Federativa do Brasil de 1988, formalizou o processo que possibilita a participação das coletividades nas ações de gerenciamento

\footnotetext{
24 PEREZ, Marcos Augusto. A administração pública democrática: institutos de participação popular na administração pública. Belo Horizonte: Fórum. 2004. p. 62

${ }^{25}$ DENHARDT, Robert. Teoria geral de organizações públicas. p. 173.

${ }^{26}$ DI PIETRO, Maria Sylvia Zanella. Polícia do meio ambiente. Revista Foresense: Rio de Janeiro, v.317, 1992. p.179-187

${ }^{27}$ MUNFORD, L. (1982) A cidade na história: suas origens, desenvolvimento e perspectivas. São Paulo: Martins Fontes,1965. p. 400-450
} 
SILVA, Marcos Vinicius Viana da; SILVA, José Everton da. O estatuto da cidade, uma necessidade social e ambiental no sistema democrático. Revista Eletrônica Direito e Política, Programa de PósGraduação Stricto Sensu em Ciência Jurídica da UNIVALI, Itajaí, v.10, n.1, edição especial de 2015. Disponível em: www.univali.br/direitoepolitica - ISSN 1980-7791.

público, tendo em vista que a ideia central era a consolidação da democracia no país.

Assim, o tema da descentralização tornou-se um consenso nos últimos anos entre correntes ideológicas à direita e à esquerda, adquirindo um lugar de destaque no processo de reforma do Estado $^{28}$.

A gestão democrática da cidade segundo Fiorillo $^{29}$ está pautada como sendo a base para o seu desenvolvimento sustentável e tem como diretrizes os preceitos democráticos dispostos na Constituição da República Federativa do Brasil de 1988, referendados no artigo 20, II, da lei no 10.257 de 2001 - Estatuto da Cidade $^{30}$, qual seja "a gestão democrática por meio da participação da população e de associações representativas dos vários segmentos da comunidade, na formulação, execução, acompanhamento de planos, de desenvolvimento urbano".

Neste sentido, a democracia participativa, é um instrumento de garantia dos direitos fundamentais, reunidos, por sua vez, no direito à cidade. Assim, segundo o sistema teórico de Habermas ${ }^{31}$, "é dedicado a revelar a possibilidade da razão, emancipação e racional-crítica latente de comunicação em instituições modernas e na capacidade humana para deliberar e defender os interesses racionais".

Para Habermas ${ }^{32}$, "esfera ou espaço público é um fenômeno social elementar, do mesmo modo que a ação, o ator, o grupo ou a coletividade; porém, ele não é arrolado entre os conceitos tradicionais elaborados para descrever a ordem social".

\footnotetext{
28 TEMER, Michel. Elementos de direito constitucional. 18 ed. São Paulo: Malheiros, 2001. p. 27.

29 FIORILLO, Celso Antônio Pacheco. Estatuto da cidade comentado: lei 10.257/2001: lei do meio ambiente artificial. p.114.

${ }^{30}$ Estatuto da cidade: guia para implementação pelos municípios e cidadãos: Lei n.10.257,10 de julho de 2001. p. 32

${ }^{31}$ HABERMAS, Jürgen. Teoría de la acción comunicativa. Madri: Taurus, 1987.

32 HABERMAS, Jürgen. Direito e Democracia: entre facticidade e validade. p.92
} 
SILVA, Marcos Vinicius Viana da; SILVA, José Everton da. O estatuto da cidade, uma necessidade social e ambiental no sistema democrático. Revista Eletrônica Direito e Política, Programa de PósGraduação Stricto Sensu em Ciência Jurídica da UNIVALI, Itajaí, v.10, n.1, edição especial de 2015. Disponível em: www.univali.br/direitoepolitica - ISSN 1980-7791.

A esfera pública não pode ser entendida como uma instituição, nem como uma organização, pois, ela não constitui uma estrutura normativa capaz de diferenciar entre competências e papéis, nem regula o modo de pertença a uma organização, etc. Tampouco ela constitui um sistema, pois, mesmo que seja possível delinear seus limites internos, exteriormente ela se caracteriza através de horizontes abertos, permeáveis e deslocáveis. A esfera pública pode ser descrita como uma rede adequada para a comunicação de conteúdos, tomadas de posição e opiniões; nela os fluxos comunicacionais são filtrados e sintetizados, a ponto de se condensarem em opiniões públicas enfeixadas em temas específicos. Do mesmo modo que o mundo da vida tomado globalmente, a esfera pública se reproduz através do agir comunicativo, implicando apenas o domínio de uma linguagem natural; ela está em sintonia com a compreensibilidade geral da prática comunicativa cotidiana. ${ }^{33}$

A noção de esfera pública ocupa posição de destaque na teoria habermasiana como arena de formação da vontade coletiva, nas ideias de Vieira ${ }^{34}$.

É o espaço do debate público, do embate dos diversos atores da sociedade. Trata-se de um espaço público autônomo apresentando uma dupla dimensão: de um lado, desenvolve processos de formação democrática de opinião pública e da vontade política coletiva; de outro, vincula-se a um projeto de práxis democrática radical, em que a sociedade civil é capaz de exercer seus direitos subjetivos públicos.

Já para Arendt, citada por Vieira ${ }^{35}$, o espaço público é uma instância em declínio na modernidade e que precisa ser revigorada nos moldes de uma pólis grega, tendo em vista que as grandes decisões são feitas pelas lutas e reivindicações.

Portanto, fica evidenciado que a Constituição da República Federativa do Brasil de 1988 estabeleceu como uma das formas de gestão democrática, a participação da sociedade civil na implementação do Plano Diretor, permitindo

\footnotetext{
33 HABERMAS, Jürgen. Direito e Democracia: entre facticidade e validade. p.92

34 VIEIRA, José Ribas. A perspectiva do espaço público na compreensão democrática do direito. Revista Jurídica da PUC do Rio de Janeiro. Disponível em: <http://www.pucrio.br/sobrepuc/depto/direito/revista/online/rev07ribas19.html>. Acesso em: 08 jan. 2013. p.63

35 VIEIRA, Liszt. Os argonautas da cidadania: a sociedade civil na globalização. Rio de Janeiro: Editora Record, 2001.
} 
SILVA, Marcos Vinicius Viana da; SILVA, José Everton da. O estatuto da cidade, uma necessidade social e ambiental no sistema democrático. Revista Eletrônica Direito e Política, Programa de PósGraduação Stricto Sensu em Ciência Jurídica da UNIVALI, Itajaí, v.10, n.1, edição especial de 2015. Disponível em: www.univali.br/direitoepolitica - ISSN 1980-7791.

não apenas mudanças na forma de relação entre o governo e a sociedade, mas reforçando a importância do papel das coletividades no processo político ${ }^{36}$.

A lei no 10.257/2001 - Estatuto da Cidade $^{37}$ - referendou em seu artigo 10-II, a gestão democrática ao dispor "[...] da participação da população e de associações representativas dos vários segmentos da comunidade na formulação, execução e acompanhamento de planos, programas e projetos de desenvolvimento urbano".

Com efeito, a gestão democrática da cidade é reconhecida como "uma diretriz para o desenvolvimento sustentável, com base nos preceitos constitucionais da democracia participativa, da cidadania, da soberania e participação popular"38, reforçando o propósito de que a democracia participativa é um instrumento de garantia dos direitos fundamentais, reunidos por sua vez, no direito à cidade, viabilizando, assim, que a mesma possa ser efetivada através do seu Plano Diretor.

Portanto, se restou evidenciado a importância da participação popular na gestão democrática das cidades, é imprescindível estabelecer quais são os instrumentos, que possam viabilizar esta participação, assim, na legislação brasileira, há previsão de que o planejamento urbano de uma cidade, deve ser instituído através do Plano Diretor Municipal, que será por sua vez tutelado, na formação e composição dos conselhos gestores, audiências públicas, entre outros.

\section{PLANO DIRETOR}

No Brasil, a institucionalização do planejamento urbano se disseminou nas administrações municipais a partir de 1970, objetivando promover o

\footnotetext{
${ }^{36}$ Estatuto da cidade: guia para implementação pelos municípios e cidadãos: Lei n.10.257,10 de julho de 2001. p. 32

${ }^{37}$ Estatuto da cidade: guia para implementação pelos municípios e cidadãos: Lei n.10.257,10 de julho de 2001. p. 34

${ }^{38}$ Estatuto da cidade: guia para implementação pelos municípios e cidadãos: Lei n.10.257,10 de julho de 2001. p. 32
} 
SILVA, Marcos Vinicius Viana da; SILVA, José Everton da. O estatuto da cidade, uma necessidade social e ambiental no sistema democrático. Revista Eletrônica Direito e Política, Programa de PósGraduação Stricto Sensu em Ciência Jurídica da UNIVALI, Itajaí, v.10, n.1, edição especial de 2015. Disponível em: www.univali.br/direitoepolitica - ISSN 1980-7791.

desenvolvimento integrado diante da explosão no processo de urbanização. Nos anos setenta, era denominado "Plano Diretor de Desenvolvimento Integrado", com a perspectiva de que as cidades fossem planejadas de modo padronizado, até que atingissem um "modelo ideal" com base na "teoria do zoneamento"39.

No entanto, pode-se dizer que este modelo tido como "ideal", politicamente representava a ideia, segundo consta no Guia do Estatuto da Cidade 40 , "de um poder central associado a um Estado forte e capitalizado, que impõe e controla este projeto sobre o cidadão, [...] diante de uma sociedade civil silenciada".

Ao longo do tempo, os padrões centralizados de planejamento foram ganhando oposição, de modo especial pelos movimentos sociais urbanos, que ansiavam por reformas no ordenamento jurídico e questionavam sobre a "legalidade urbanística", principalmente com relação ao conceito de "cidade real" (aquela idealizada como modelo). Além disso, veio a resultar na urbanização irregular e clandestina que se formavam nos arredores das cidades ${ }^{41}$.

A Emenda Popular da Reforma Urbana foi encaminhada ao Congresso Constituinte pelo Movimento Nacional pela Reforma Urbana como um novo paradigma, partindo do conceito de que uma cidade é produzida pela multiplicidade de agentes que "devem ter sua ação coordenada, não em função de um modelo produzido em escritórios, mas a partir de um pacto - a cidade que queremos - que corresponda a um interesse público da cidade ${ }^{42}$.

O Plano Diretor é obrigatório para os Municípios com mais de 20 mil habitantes e aglomerações urbanas, sob pena dos administradores serem punidos por atos de improbidade administrativa, embora tal obrigatoriedade não vinculativa já

${ }^{39}$ Estatuto da cidade: guia para implementação pelos municípios e cidadãos: Lei n.10.257,10 de julho de 2001. p. 32

${ }^{40}$ Estatuto da cidade: guia para implementação pelos municípios e cidadãos: Lei n.10.257,10 de julho de 2001. p. 39

${ }^{41}$ Estatuto da cidade: guia para implementação pelos municípios e cidadãos: Lei n.10.257,10 de julho de 2001. p. 40.

${ }^{42}$ Estatuto da cidade: guia para implementação pelos municípios e cidadãos: Lei n.10.257,10 de julho de 2001. p. 37. 
SILVA, Marcos Vinicius Viana da; SILVA, José Everton da. O estatuto da cidade, uma necessidade social e ambiental no sistema democrático. Revista Eletrônica Direito e Política, Programa de PósGraduação Stricto Sensu em Ciência Jurídica da UNIVALI, Itajaí, v.10, n.1, edição especial de 2015. Disponível em: www.univali.br/direitoepolitica - ISSN 1980-7791.

constasse no artigo 182 e parágrafos da Constituição da República Federativa do Brasil de 1988.

Tal obrigatoriedade e disciplina legal veio com a Lei Federal, no. 10.257, de 10 de julho de 2001- Estatuto da Cidade $^{43}$, em vigor desde outubro de 2001, regulamentando os artigos 182 e 183 da Constituição da República Federativa do Brasil de 1988 no que trata da política urbana, especificamente da função social da propriedade.

Sendo uma Lei Federal, a Lei n. 10.257/2001 - Estatuto da Cidade - define de modo geral diretrizes de políticas urbanas a serem aplicadas nos municípios brasileiros.

Questões importantes para a vida nas cidades brasileiras são objetos desta Lei, tais como a regularização fundiária, em especial nas áreas de baixa renda; o uso e a ocupação do solo urbano e a habitação em especial em áreas subutilizadas situadas dentro da cidade; a relação entre a cidade e o campo, onde se constrói a expansão urbana, muitas vezes sem controle; a relação entre a cidade e seu meio ambiente, para garantir segurança e qualidade do habitat; as parcerias entre setores público e privado nas intervenções urbanísticas, etc.

Assim, o plano diretor é um instrumento normativo competente para definir a função social da propriedade para fins urbanísticos; é o mais importante instrumento de planificação urbana, obrigatório para os Municípios; deve ser aprovado por lei e tem, entre outras prerrogativas, a condição de definir qual a função a ser atingida pela propriedade urbana e de viabilizar a adoção dos demais instrumentos de implementação da política (parcelamento, edificação ou utilização compulsória, IPTU progressivo, desapropriação com pagamento de títulos, direito de preempção, outorga onerosa do direito de construir, operações urbanas consorciadas e transferência do direito de construir).

\footnotetext{
${ }^{43}$ Estatuto da cidade: guia para implementação pelos municípios e cidadãos: Lei n.10.257,10 de julho de 2001. p. 41.
} 
SILVA, Marcos Vinicius Viana da; SILVA, José Everton da. O estatuto da cidade, uma necessidade social e ambiental no sistema democrático. Revista Eletrônica Direito e Política, Programa de PósGraduação Stricto Sensu em Ciência Jurídica da UNIVALI, Itajaí, v.10, n.1, edição especial de 2015. Disponível em: www.univali.br/direitoepolitica - ISSN 1980-7791.

No que se refere à estrutura do Plano Diretor, esta é estabelecida em conformidade com as diretrizes expressas no Estatuto da Cidade $^{44}$, que por sua vez tutela a participação da sociedade civil organizada na implementação das políticas públicas urbanísticas, visando definir o destino das diferentes regiões do município, de modo que seja definida a sua cartografia, a denominada "macrozoneamento".

Segundo Machado45 "o macrozoneamento consiste em definir o território em parcelas nas quais se autorizam ou interdita-se o exercício de determinadas atividades", de onde se conclui, portanto, que o macrozoneamento é a base fundamental para definir o uso e a ocupação do solo nas cidades.

A Lei n.10.257/2001 - Estatuto da Cidade dispõe, ainda, sobre o detalhamento deste macrozoneamento e menciona que "a partir dele pode-se estabelecer um zoneamento mais detalhado no interior (chamados também de zoneamento ou microzoneamento), das macrozonas ou não, entretanto é fundamental que estejam contidas no Plano Diretor" ${ }^{46}$.

Diante da pesquisa realizada, fica claro que o estabelecimento das normas dispostas no Plano Diretor, em consonância com a Lei n.10.257/2001 - Estatuto da Cidade e fundamentada nos dispositivos constitucionais, nas palavras de Cavedon $^{47}$, ao regular o uso e ocupação do solo, "consubstanciam-se em importante instrumento de gestão [...] ao impor limitações ao uso da propriedade urbana visando adequá-los aos interesses da coletividade", por conseguinte, a lei que regulamenta o plano diretor é eficaz no limite de suas determinações, tornando nulos os atos municipais contrários às normas do plano

\footnotetext{
${ }^{44}$ Plano diretor: pode ser definido como um conjunto de princípios e regras orientadoras da ação dos agentes que constroem e utilizam o espaço urbano, partindo de uma leitura real da cidade, envolvendo temas e questões relativas aos aspectos urbanos, sociais, econômicos e ambientais, que embasa a formulação de hipóteses realistas sobre opções de desenvolvimento e modelos de territorialização. Estatuto da Cidade: guia para implementação pelos municípios e cidadãos:
}

45 MACHADO, Paulo Affonso Leme. Direito ambiental brasileiro. 7.ed. São Paulo: Malheiros. 1999. p. 782

${ }^{46}$ Estatuto da cidade: guia para implementação pelos municípios e cidadãos: Lei n.10.257,10 de julho de 2001. p. 41.

${ }^{47}$ CAVEDON, Fernanda de Salles. Função social e ambiental da propriedade. p. 73 
SILVA, Marcos Vinicius Viana da; SILVA, José Everton da. O estatuto da cidade, uma necessidade social e ambiental no sistema democrático. Revista Eletrônica Direito e Política, Programa de PósGraduação Stricto Sensu em Ciência Jurídica da UNIVALI, Itajaí, v.10, n.1, edição especial de 2015. Disponível em: www.univali.br/direitoepolitica - ISSN 1980-7791.

diretor - assim denominado por estabelecer as diretrizes gerais de desenvolvimento social, econômico, territorial e institucional do município.

\section{PARTICIPAÇÃo POPULAR COMO PRINCÍPIO E COMO CONDIÇÃO DE LEGITIMAÇÃO}

A Constituição da República Federativa do Brasil de 1988 e a Lei n.10.257/2001 ${ }^{48}$ - Estatuto da Cidade - trazem elementos fundamentais para atacar o processo histórico de desenvolvimento desigual das nossas cidades: a função social da cidade e da propriedade e a participação popular no planejamento e gestão das cidades. Neste sentido o Direito, na visão de Freitag ${ }^{49}$, a partir dos estudos de Habermas, ocupa essa função de integração social.

Habermas vê no direito uma força e função integradoras, que cimentam e harmonizam o mundo vivido com a esfera sistêmica da economia e da administração, impedindo que esse sistema efetue a colonização do mundo-da-vida, ameaçando sua integridade. Desse modo o direito controla e ordena os excessos da economia e do poder, aproxima a facticidade da validade, os fatos das normas, redefinindo e remodelando histórica e normativamente suas relações. Enfim é o direito discursivo a única forma aceitável de gerar a facticidade e a validade de uma norma.

Este processo de elaboração do Plano Diretor começa pela instalação do Núcleo Gestor, composto de representantes do poder público e da sociedade civil. Ele deve expressar a diversidade de todos os setores sociais atuantes no município como já exaustivamente manifestado, e sua inobservância reveste-o de ilegalidade e inconstitucionalidade, uma vez que sua base é eivada de vícios, portanto, não basta que a sociedade civil tome apenas conhecimento da existência do Plano Diretor, é imprescindível que esta possa, em conformidade com a legislação, participar e decidir sobre sua elaboração.

Predomina aqui uma visão comunitarista de participação, "a sociedade sustentase pela ação e apoio dos grupos, contrariamente às decisões atomistas do

\footnotetext{
${ }^{48}$ Estatuto da cidade: guia para implementação pelos municípios e cidadãos: Lei n.10.257,10 de julho de 2001. p. 41.

${ }^{49}$ FREITAG, B. Receita para ler Habermas. Folha de São Paulo, 30 abr. 1995. Caderno Mais! Disponível no arquivo folha. p. 5-10
} 
SILVA, Marcos Vinicius Viana da; SILVA, José Everton da. O estatuto da cidade, uma necessidade social e ambiental no sistema democrático. Revista Eletrônica Direito e Política, Programa de PósGraduação Stricto Sensu em Ciência Jurídica da UNIVALI, Itajaí, v.10, n.1, edição especial de 2015. Disponível em: www.univali.br/direitoepolitica - ISSN 1980-7791.

indivíduo no âmbito liberal. Seu principal objetivo consiste em construir uma comunidade baseada em valores centrais, como identidade comum, solidariedade, participação e integração" ${ }^{\prime 50}$.

Para Habermas ${ }^{51}$,

Os direitos subjetivos são direitos negativos que protegem os espaços da ação individual, na medida em que fundamentam pretensões, reclamáveis judicialmente, contra intervenções ilícitas na liberdade, na vida e na propriedade. A autonomia privada é garantida principalmente através do direito de fechar contratos, de adquirir, herdar ou alienar propriedade.

Para Maia ${ }^{52}$, Habermas reconhece a importância da soberania popular e do aspecto intersubjetivo que constitui o domínio da vida política.

Nesse paradigma, a soberania popular se expressa através da formação da vontade coletiva dentro do espaço público político. O problema de como resolver a tensão entre direitos humanos e soberania popular é pensado através de uma relação interna entre estas duas ideias, reconhecendo no direito das sociedades modernas não apenas o papel de garantidor da ordem e do status quo, mas também o de um mecanismo fundamental de integração social.

Habermas por acreditar no poder comunicativo e na ação social, diverge portanto dos liberais, na medida em que apreende os aspectos individuais secundariamente.

\subsection{A participação popular na criação de plano diretor: uma garantia constitucional}

Para manter a coerência do sistema, foram criados os controles de constitucionalidade, que como o próprio nome explica, são mecanismos que

\footnotetext{
${ }^{50}$ VIEIRA, Liszt. Os argonautas da cidadania: a sociedade civil na globalização. p.39-40

${ }^{51}$ HABERMAS, Jürgen. Direito e Democracia: entre facticidade e validade. p.116-117

52 MAIA, Antônio C. Revista Jurídica da PUC-RJ. Disponível em: <http://wwwpucrio.br/sobrepuc/depto/direito/revista/online/rev11antonio.html>.
} 
SILVA, Marcos Vinicius Viana da; SILVA, José Everton da. O estatuto da cidade, uma necessidade social e ambiental no sistema democrático. Revista Eletrônica Direito e Política, Programa de PósGraduação Stricto Sensu em Ciência Jurídica da UNIVALI, Itajaí, v.10, n.1, edição especial de 2015. Disponível em: www.univali.br/direitoepolitica - ISSN 1980-7791.

visam expurgar do sistema as normas que não são constitucionais, ou seja, que estejam em conflito com a Constituição da República Federativa do Brasil de 1988.

Segundo $\operatorname{Temer}^{53}$, numa conceituação bastante simples e objetiva, "controlar a constitucionalidade de ato normativo significa impedir a subsistência da eficácia de norma contrária à Constituição", e conforme dispõe o artigo 102 §20 da Constituição da República Federativa do Brasil de $1988^{54}$, o processamento das ações visando o controle de constitucionalidade de leis ou atos estaduais e municipais será definido pela corte.

Com relação a este aspecto, os Tribunais de Justiça Estaduais Brasileiros têm admitido, em números incontáveis, ações diretas de inconstitucionalidade relacionadas à falta de participação popular, não apenas nos processos de elaboração e implantação de planos diretores, mas também nas mais diversas situações que impliquem direta ou indiretamente na modificação de preceitos do plano diretor, sem que houvesse efetivamente a participação popular nas decisões da cidade.

De acordo com pesquisa realizada, foram localizadas em torno de 40.000 ações em todo o país, milhares ainda em tramitação, todas, entretanto, questionando os preceitos contidos nos dispositivos legais do Brasil, já exaustivamente explicitadas no presente artigo, sobre a falta de gestão democrática ou participativa.

A partir deste número, se for considerar que atualmente o Brasil tem 5.564 municípios, segundo dados do Instituto Brasileiro de Geografia e Estatístico IBGE, destes, cerca de 1.700 atendem o requisito de ter no mínimo 20.000 moradores para implantação de plano diretor, a existência de cerca de 40.000 ações evidencia, que a participação da sociedade na discussão dos seus rumos e destinos, ainda é um sonho distante.

\footnotetext{
53 TEMER, Michel. Elementos de direito constitucional. p. 30-40

54 BRASIL. Vade Mecum. /obra coletiva de autoria da Editora Saraiva com a colaboração de Luiz Roberto Curia, Márcia Cristina Vaz dos Santos Windt e Lívia Céspedes. p.40
} 
SILVA, Marcos Vinicius Viana da; SILVA, José Everton da. O estatuto da cidade, uma necessidade social e ambiental no sistema democrático. Revista Eletrônica Direito e Política, Programa de PósGraduação Stricto Sensu em Ciência Jurídica da UNIVALI, Itajaí, v.10, n.1, edição especial de 2015. Disponível em: www.univali.br/direitoepolitica - ISSN 1980-7791.

\section{CONSIDERAÇÕES FINAIS}

A ideia de um Estado democrático de direito pleno, está efetivamente embasada na participação da sociedade civil em todas as suas decisões. Imaginar que o destino de uma cidade, estado ou país esteja entregue às mãos de alguns poucos é negar todos os princípios constitucionais da Cidadania e da Dignidade da Pessoa Humana.

A premissa que se faz necessária é de que a discussão pública, dos problemas da cidade, mais do que um preceito meramente jurídico, é antes um conceito de cidadania. A gestão e governança pública, no inicio do século XXI, coroando uma discussão do final do século $X X$, precisa ser aprofundada.

O conceito de sustentabilidade se reforça no contexto de discussão democrática do Plano Diretor, a sociedade como um todo, tende a ser muito mais sensível a discussão ambiental, do que pequenos grupos, geralmente interessados em preservar ganhos de natureza econômica. A governança municipal, tende a ser mais "ambiental" e menos agressora, num critério de democratização das discussões e elaboração dos planos diretores.

Infelizmente, os dados apresentados nesta pesquisa, com mais de 40.000 processos judiciais, discutindo a não implementação da participação popular nas esferas de construção do Plano Diretor dos municípios brasileiros, deixa claro, que como conceito de discussão democrática, o plano diretor ainda está muito longe de espelhar o desejo do constituinte de 1988.

Radicalmente aprofundar a participação popular, acentuar a governabilidade democrática, são os caminhos vislumbrados em 1988, pela chamada carta cidadã, estes são os caminhos que entendemos deve nortear a elaboração dos planos diretores, país afora.

Mais do que uma simples discussão sobre legalidade ou ilegalidade a cerca da aprovação de planos diretores sem a devida as sociedades envolvidas, representa uma ausência total de legitimação do ordenamento jurídico aprovado, e uma compreensível falta de sintonia entre o texto aprovado e a população envolvida. 
SILVA, Marcos Vinicius Viana da; SILVA, José Everton da. O estatuto da cidade, uma necessidade social e ambiental no sistema democrático. Revista Eletrônica Direito e Política, Programa de PósGraduação Stricto Sensu em Ciência Jurídica da UNIVALI, Itajaí, v.10, n.1, edição especial de 2015. Disponível em: www.univali.br/direitoepolitica - ISSN 1980-7791.

Em tempos de velocidade de informações e acesso a diferentes formas de comunicação, não respeitar um direito mínimo da cidadania, que é o direito de participação, voz e voto, nos remete a períodos difíceis de nossa história recente que todos preferimos ver ultrapassado.

\section{REFERÊNCIAS DAS FONTES CITADAS}

BENEVOLO, Leonardo- História da cidade, Perspectiva, 3. ed. 1997.

BOBBIO, Norberto. A era dos direitos. Trad. Carlos Nelson Coutinho. Campus, 1992.

BRASIL. Vade Mecum. /obra coletiva de autoria da Editora Saraiva com a colaboração de Luiz Roberto Curia, Márcia Cristina Vaz dos Santos Windt e Lívia Céspedes, 12 ed. atual. e ampl. - São Paulo: Saraiva, 2012.

CAVEDON, Fernanda de Salles. Função social e ambiental da propriedade. Florianópolis: Visualbooks, 2003.

CAVEDON, Fernanda de Salles; DIEHL, Francelise Pantoja. A influência da política de desenvolvimento urbano no uso da zona costeira de Bombinhas (SC)- XI Semana Nacional da Oceanografia. Anais>Rio Grande: Fundação Universidade de Rio Grande, 1998.

DENHARDT, Robert. Teoria geral de organizações públicas. (trad. Prof. Francisco G.Heidemann. Thompson/ Wadsworth. 2004.

Declaração do Rio. Declaração da comissão de Desenvolvimento sustentável da ONU. 1992

DI PIETRO, Maria Sylvia Zanella. Polícia do meio ambiente. Revista Foresense: Rio de Janeiro, v.317, 1992.

Estatuto da cidade: guia para implementação pelos municípios e cidadãos: Lei n.10.257,10 de julho de 2001, $3^{a}$ Ed. Brasília: Câmara dos Deputados, Coordenação de Publicações. 2005.

FIORILLO, Celso Antônio Pacheco. Estatuto da cidade comentado: lei 10.257/2001: lei do meio ambiente artificial. 2.ed. rev. atual. e ampl. São Paulo: Editora Revista dos Tribunais, 2005.

FIORILlO, Celso Antônio Pacheco. Curso de direito ambiental brasileiro. 4.ed. ampl. - São Paulo: Saraiva, 2003.

FREITAG, B. Receita para ler Habermas. Folha de São Paulo, 30 abr. 1995. Caderno Mais! Disponível no arquivo folha. 
SILVA, Marcos Vinicius Viana da; SILVA, José Everton da. O estatuto da cidade, uma necessidade social e ambiental no sistema democrático. Revista Eletrônica Direito e Política, Programa de PósGraduação Stricto Sensu em Ciência Jurídica da UNIVALI, Itajaí, v.10, n.1, edição especial de 2015. Disponível em: www.univali.br/direitoepolitica - ISSN 1980-7791.

HABERMAS, Jürgen. Teoría de la acción comunicativa. Madri: Taurus, 1987.

HABERMAS, Jürgen. Direito e Democracia: entre facticidade e validade. Tradução de Flávio Beno Siebeneichler. Rio de Janeiro: Tempo Brasileiro, 1997.

KELSEN, Hans. Teoria geral do direito e do Estado. Tradução de Luís Carlos Borges. São Paulo: Martins Fontes. 1990.

LAYRARGUES, Philippe Pomier. Do ecodesenvolvimento ao desenvolvimento sustentável:evolução de um conceito? São Paulo.1997. Acessível em: http://material.nerea-Investiga.org/publicacoes/user_35/FICH_ES_32.pdf

LE CORBUSIER. A Carta de Atenas; 1993, teses 15 e 73 de Atenashttp://www.infopedia.pt/\$carta-de-atenas - consulta em 30.10.2011.

MAIA, Antônio C. Revista Jurídica da PUC-RJ. Disponível em: $<$ http://wwwpuc-

rio.br/sobrepuc/depto/direito/revista/online/rev11antonio.html>.

MACHADO, Paulo Affonso Leme. Direito ambiental brasileiro. 7.ed. São Paulo: Malheiros. 1999.

MUNFORD, L. (1982) A cidade na história: suas origens, desenvolvimento e perspectivas. São Paulo: Martins Fontes,1965.

Nosso Futuro Comum/Comissão Mundial Sobre Meio Ambiente e Desenvolvimento. 1992

PASOLD, Cesar Luiz. Metodologia da Pesquisa Jurídica: Teoria e Prática. $12^{a}$ Edição revisada. São Paulo: Conceito Editorial, 2011.

PEREZ, Marcos Augusto. A administração pública democrática: institutos de participação popular na administração pública. Belo Horizonte: Fórum. 2004.

SILVA, Jose Afonso. Direito urbanístico brasileiro. 2.ed. São Paulo: Malheiros, 1995.

SARTORI, Giovanni. A teoria da democracia revisitada: 0 debate contemporâneo. v. 1, [s. I.], Editora Ática, 1994.

SOUZA, Maria Adélia. Governo urbano. São Paulo: Nobel, 1988.

TEMER, Michel. Elementos de direito constitucional. 18 ed. São Paulo: Malheiros, 2001.

VIEIRA, José Ribas. A perspectiva do espaço público na compreensão democrática do direito. Revista Jurídica da PUC do Rio de Janeiro. Disponível em:

$<$ http://www.pucrio.br/sobrepuc/depto/direito/revista/online/rev07ribas19.html>. Acesso em: 08 jan. 2013. 
SILVA, Marcos Vinicius Viana da; SILVA, José Everton da. O estatuto da cidade, uma necessidade social e ambiental no sistema democrático. Revista Eletrônica Direito e Política, Programa de PósGraduação Stricto Sensu em Ciência Jurídica da UNIVALI, Itajaí, v.10, n.1, edição especial de 2015. Disponível em: www.univali.br/direitoepolitica - ISSN 1980-7791.

VIEIRA, Liszt. Os argonautas da cidadania: a sociedade civil na globalização. Rio de Janeiro: Editora Record, 2001.

Submetido em: Setembro/2014

Aprovado em: Outubro/2014 